\title{
Scurvy presenting as hematochezia
}

A 56-year-old woman was admitted because of hematochezia and normocytic anemia. Her previous medical history was notable for asthma and severe oropharyngeal dysphagia from a tight cricopharyngeus, which had been demonstrated on a modified barium swallow 6 months previously, occupying over $75 \%$ of the lumen during deglutition. Physical examination was notable for hematochezia, along with innumerable purpuric macules, several small purpuric papules that were coalescing into plaques, and ecchymotic indurated patches involving the groin and both legs.

The results of blood analysis showed anemia (hemoglobin $8.5 \mathrm{~g} / \mathrm{dL}$ ), an elevated C-reactive protein (CRP) at $37.1 \mathrm{mg} / \mathrm{L}$, and an elevated international normalized ratio (INR) of 1.5, with normal levels of B12, folate, and vitamin D, and an otherwise nondiagnostic work-up for vasculitis and autoimmune markers. Histopathological analysis of skin biopsies demonstrated hematomas. The patient's ascorbic acid level was found to be undetectable $(<0.1 \mathrm{mg} / \mathrm{dL})$, therefore confirming the diagnosis of scurvy secondary to her prolonged oropharyngeal dysphagia that had lead to dietary inadequacies.

Upper gastrointestinal endoscopy and colonoscopy revealed patches of submucosal hemorrhage in the stomach, small bowel ( $\bullet$ Fig. 1 a), and colon ( $\bullet$ Fig. 1 b,c). To pass the cricopharyngeus, the upper gastrointestinal endoscopy had to be performed using a 5.5-mm diameter endoscope.

The patient was given intravenous ascorbic acid $250 \mathrm{mg}$ twice daily, with improvement of her skin lesions being noted within 24 hours of administration. Along with dietary modifications, her ascorbic acid replacement was continued for 3 days intravenously, before being changed over to $250 \mathrm{mg}$ twice daily by intramuscular injections for 14 days, and subsequently to daily intramuscular injections for a further 3 weeks, followed by ongoing oral supplementation.

Scurvy, the disease caused by vitamin C deficiency, is uncommon in industrialized countries; however, it can occur in people who are alcoholic with poor nutrition, in elderly people who are isolated, and in people who are institutionalized. The hallmark features include lethargy, purpuric lesions on the lower extremities, myalgias, and gingival bleeding. Common misdiagnoses include blood dyscrasias and vasculitis [1]. If left untreated, scurvy leads to infection and death. Gastrointestinal manifestations have rarely been reported as causing intestinal changes [2]. Treatment includes dietary modification and intravenous ascorbic acid, with resolution of lesions taking only days, followed by daily replacement leading to normalization of ascorbic acid levels in 3-4 weeks.
Endoscopy_UCTN_Code_CCL_1AB_2AD_3AF

\section{Competing interests: None}

\section{William C. Palmer, Maria Vazquez- Roche}

Department of Gastroenterology and Hepatology, Mayo Clinic, Jacksonville, Florida, USA

\section{References}

1 Pimentel L. Scurvy: historical review and current diagnostic approach. Am J Emerg Med 2003; 21: 328-332

2 Schuman RW, Rahmin M, Dannenberg AJ. Scurvy and the gastrointestinal tract. Gastrointest Endosc 1997; 45: 195-196

\section{Bibliography}

DoI http://dx.doi.org/

10.1055/s-0034-1365815

Endoscopy 2014; 46: E292

(c) Georg Thieme Verlag KG

Stuttgart · New York

ISSN 0013-726X

\section{Corresponding author \\ William Palmer, MD}

Mayo Clinic

4500 San Pablo Road S

Jacksonville

FL 32224

USA

Palmer.william@mayo.edu

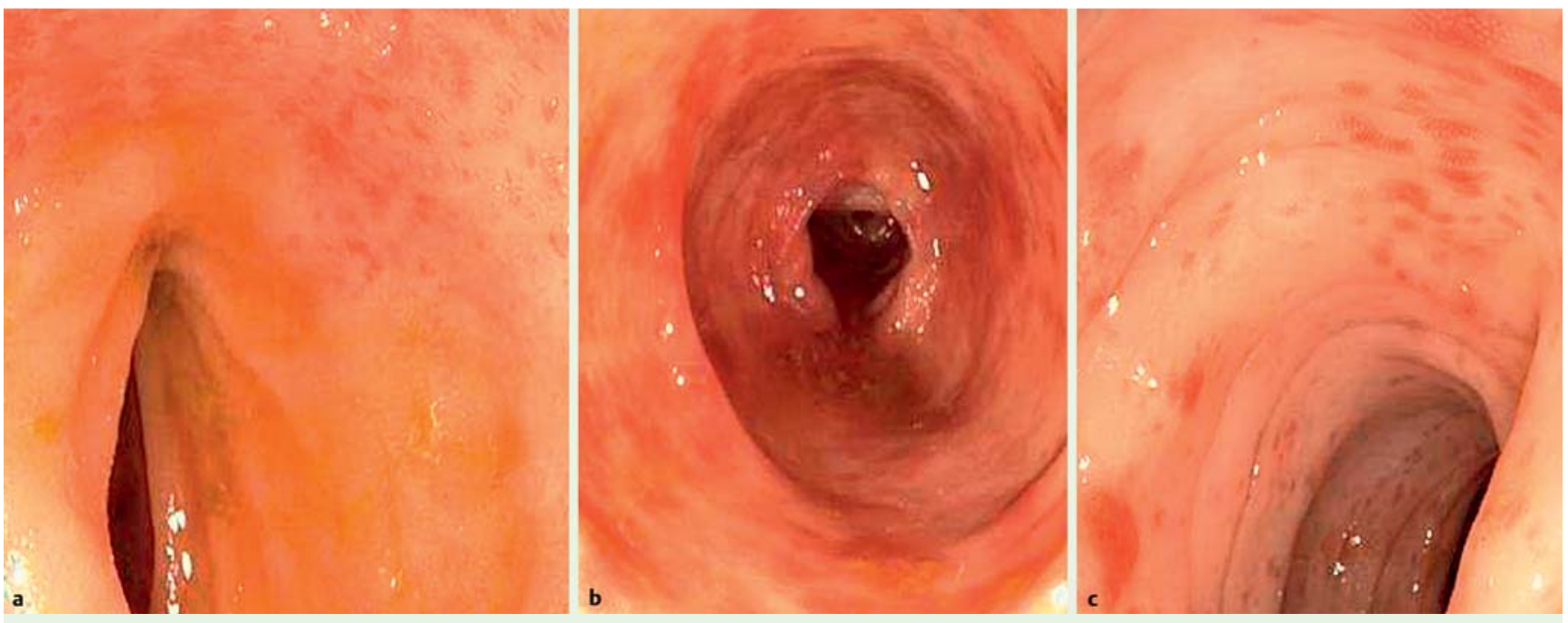

Fig. 1 Endoscopic views showing patches of submucosal hemorrhage in the mucosa of: a the terminal ileum; $\mathbf{b}, \mathbf{c}$ the colon. 